\title{
BMJ
}

\section{Social variations in access to hospital care for patients with colorectal, breast, and lung cancer between 1999 and 2006: retrospective analysis of hospital episode statistics}

\author{
Rosalind Raine, professor of health care evaluation, ${ }^{1}$ Wun Wong, honorary research fellow, ${ }^{1}$ Shaun Scholes, \\ honorary research fellow, ${ }^{1}$ Charlotte Ashton, specialty registrar in public health, ${ }^{1}$ Austin Obichere, consultant \\ colorectal surgeon, ${ }^{2}$ Gareth Ambler, lecturer in statistics ${ }^{3}$
}

${ }^{1}$ Department of Epidemiology and Public Health, University College London, London WC1E 6BT

${ }^{2}$ University College London Hospital, London NW1 2PG

${ }^{3}$ Department of Statistical Science, University College London

Correspondence to: R Raine r.raine@ucl.ac.uk

Cite this as: $B M J$ 2010;340:b5479 doi:10.1136/bmj.b5479

\section{ABSTRACT}

Objectives To determine the extent to which type of hospital admission (emergency compared with elective) and surgical procedure varied by socioeconomic circumstances, age, sex, and year of admission for colorectal, breast, and lung cancer.

Design Repeated cross sectional study with data from individual patients, 1 April 1999 to 31 March 2006.

Setting Hospital episode statistics (HES) dataset.

Participants 564821 patients aged 50 and over admitted with a diagnosis of colorectal, breast, or lung cancer.

Main outcome measures Proportion of patients admitted as emergencies, and the proportion receiving the recommended surgical treatment.

Results Patients from deprived areas, older people, and women were more likely to be admitted as emergencies. For example, the adjusted odds ratio for patients with breast cancer in the least compared with most deprived fifth of deprivation was 0.63 ( $95 \%$ confidence interval 0.60 to 0.66 ) and the adjusted odds ratio for patients with lung cancer aged 80-89 compared with those aged 50-59 was 3.13 (2.93 to 3.34). There were some improvements in disparities between age groups but not for patients living in deprived areas over time. Patients from deprived areas were less likely to receive preferred procedures for rectal, breast, and lung cancer. These findings did not improve with time. For example, $67.4 \%$ (3529/5237) of patients in the most deprived fifth of deprivation had anterior resection for rectal cancer compared with $75.5 \%$ (4497/5959) of patients in the least deprived fifth $(1.34,1.22$ to 1.47$)$. Over half $(54.0 \%, 11256 / 20849)$ of patients in the most deprived fifth of deprivation had breast conserving surgery compared with $63.7 \%(18445 / 28960)$ of patients in the least deprived fifth (1.21, 1.16 to 1.26$)$. Men were less likely than women to undergo anterior resection and lung cancer resection and older people were less likely to receive breast conserving surgery and lung cancer resection. For example, the adjusted odds ratio for lung cancer patients aged 80-89 compared with those aged 50-59 was 0.52 (0.46 to 0.59). Conclusions Despite the implementation of the NHS Cancer Plan, social factors still strongly influence access to and the provision of care.

\section{INTRODUCTION}

During the mid-1990s it became increasingly apparent that cancer survival in England was lower than the European average.$^{1-3}$ Concerns about inequalities in access to National Health Service (NHS) cancer services were also raised. ${ }^{4}$ In response, in 1995 the government produced a policy framework for commissioning cancer services - the Calman-Hine report. ${ }^{5}$ English regions took different approaches to its implementation, and geographic inequalities in access to care and to surgical site specialisation - that is, different approaches taken for different cancers - continued to be reported..$^{6-9}$ The relative lack of perceived progress and of a unified approach to implementation led to the development of the NHS Cancer Plan in 2000. ${ }^{1011}$ This brought substantial financial investment to cancer services together with detailed improving outcomes guidance on individual cancers. ${ }^{12-14}$ The plan focused on early detection, the development of clear care pathways, and service reconfiguration to allow timely referral to the most appropriate care.

The plan aimed to improve outcomes overall and to reduce health inequalities, in part through greater equity of access to health care for all those in need regardless of their socioeconomic circumstance, age, or sex. Recent evaluations of the plan have reported on progress on implementation and on outcomes. ${ }^{15-17}$ Access to health care, however, is defined differently depending on whether one's perspective focuses on human rights, health policy, or the organisation and delivery of services. ${ }^{18}$ For the latter, assessment of access requires examination both of the process of entering the health system and of use of services. The extent to which access (defined in these terms) has improved for all social groups has not been established.

We assessed this by examining social variations in trends in two key routinely available indicators of entry to and subsequent use of secondary care. We focused on the three most common cancers: colorectal, breast, and lung. Together these accounted for $64 \%$ of new cases diagnosed in $2006^{19}$ and $40 \%$ of deaths from cancer in $2007 .{ }^{20}$ To assess improvements in access to 
Finished consultant episodes for colorectal cancer (1 April 1998 - 31 March 2006) (n=1 375933 )

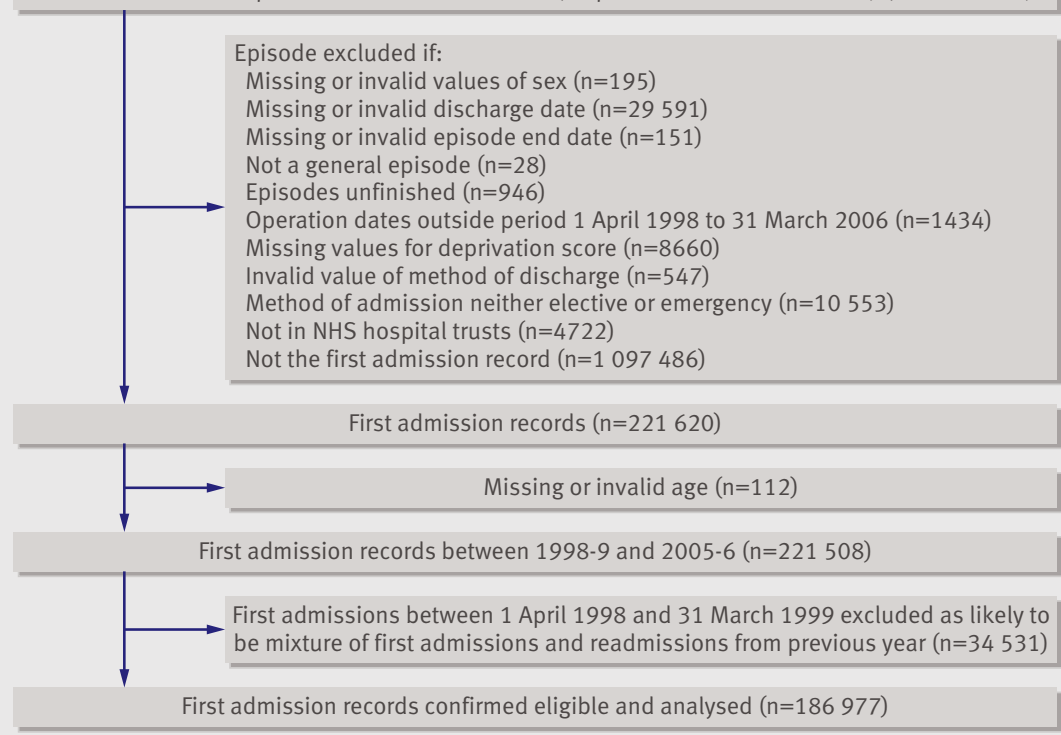

Fig 1 | Steps taken in selecting patients' records for analysis (colorectal cancer)

care, we examined type of admission, hypothesising that the commitment that every patient diagnosed with cancer would benefit from pre-planned and prebooked care would lead to a reduction in the proportion of patients admitted as emergencies. To assess improvements in treatment we examined trends in the provision of recommended surgical procedures over time. For colorectal cancer, we anticipated

Finished consultant episodes for colorectal cancer (1 April 1998 - 31 March 2006) ( $n=1375$ 933)

\begin{tabular}{|c|c|}
\hline & $\begin{array}{l}\text { Episode excluded if: } \\
\text { Missing or invalid values of sex }(n=195) \\
\text { Missing or invalid discharge date }(n=29591) \\
\text { Missing or invalid episode end date }(n=151) \\
\text { Not a general episode }(n=28) \\
\text { Episodes unfinished }(n=946) \\
\text { Operation dates outside period } 1 \text { April } 1998 \text { to } 31 \text { March } 2006(n=1434) \\
\text { Missing values for deprivation score }(n=8660) \\
\text { Invalid value of method of discharge }(n=547) \\
\text { Method of admission neither elective or emergency }(n=10553) \\
\text { Not in NHS hospital trusts }(n=4722) \\
\text { No diagnosis of rectal cancer }(n=911411) \\
\text { No admission for rectal surgery }(n=373376) \\
\text { Having both anterior resection and abdominoperineal resection }(n=21) \\
\text { Not the first admission record }(n=329)\end{array}$ \\
\hline \multicolumn{2}{|r|}{ First admission records for rectal cancer patients having surgery $(\mathrm{n}=33969)$} \\
\hline & $\begin{array}{l}\text { Exclude first admission records if: } \\
\text { Missing or invalid age }(n=3) \\
\text { Invalid operation dates }(n=42)\end{array}$ \\
\hline \multicolumn{2}{|c|}{ First admission records for rectal cancer patients between $1998-9$ and 2005-6 $(n=33924)$} \\
\hline & $\begin{array}{l}\text { First admissions between } 1 \text { April } 1998 \text { and } 31 \text { March } 1999 \text { excluded as likely to } \\
\text { be mixture of first admissions and readmissions from previous year }(n=4710)\end{array}$ \\
\hline & admission records confirmed eligible and analysed $(n=29214)$ \\
\hline
\end{tabular}

Fig 2 | Steps taken in selecting patients' records for analysis (rectal cancer) increased use of anterior resection compared with abdominoperineal resection for cancer in the lower two thirds of the rectum (that is, for rectal cancer) because improving outcomes guidance states that, whenever possible, formation of permanent stoma should be avoided. ${ }^{21}$ Anterior resection restores bowel continuity and avoids the use of a permanent stoma, whereas abdominoperineal resection results in the fashioning of a permanent colostomy. For breast cancer the improving outcomes guidance states that breast conserving surgery should be available to patients with appropriate tumours, and so we anticipated increased use of breast conserving surgery compared with mastectomy. Non-small cell cancer accounts for about $84 \%$ of lung cancers in the United Kingdom, ${ }^{22}$ and surgical resection is recommended for those with early stage disease. ${ }^{14} \mathrm{We}$ anticipated that implementation of the plan would result in earlier diagnosis and therefore higher rates of surgical resection of lung cancer over time.

We therefore determined the extent to which type of hospital admission (emergency compared with elective) and surgical procedure (anterior resection, abdominoperineal resection, breast conserving surgery, mastectomy, and lung cancer resection) varied by socioeconomic circumstances, age, sex, and year of admission for colorectal, breast, and lung cancer.

\section{METHODS}

\section{Data source}

We examined data from individual patients using the hospital episode statistics (HES) dataset. This includes demographic, diagnostic, and procedural data for all inpatient treatment delivered by NHS hospitals in England. ${ }^{23}$ About 14 million records are collected annually. The basic unit of measurement is the "finished consultant episode." This refers to a continuous period of care "administered within a particular consultant specialty at a single hospital provider. ${ }^{.24}$ Data on surgical patients are included in the year in which the episode of care ended, irrespective of the date of surgery. Diagnoses are classified with the World Health Organization's ICD-10 (international classification of disease, 10th revision). Procedures are classified according to codes from the Office for National Statistics, version 4 (OPCS-4).$^{25}$ Though data are provided on comorbid conditions, their utility in this context is limited because of a lack of information on severity and because it is not possible to delineate how these relate to pre-surgical or postoperative complications. ${ }^{26}$ Age is provided as month and year of birth. An indicator of patients' socioeconomic circumstances is available from the index of multiple deprivation ranking for each patient supplied by HES. This index is a widely used area based measure that combines seven indicators into a single deprivation score for each small area (that is, each "lower layer super output area," which covers about 1500 people) in England. The indicators comprise "income deprivation," "employment deprivation," "health deprivation and disability," "education, skills, and 
Finished consultant episodes for breast cancer (1 April 1998 - 31 March 2006) (n=856 854)

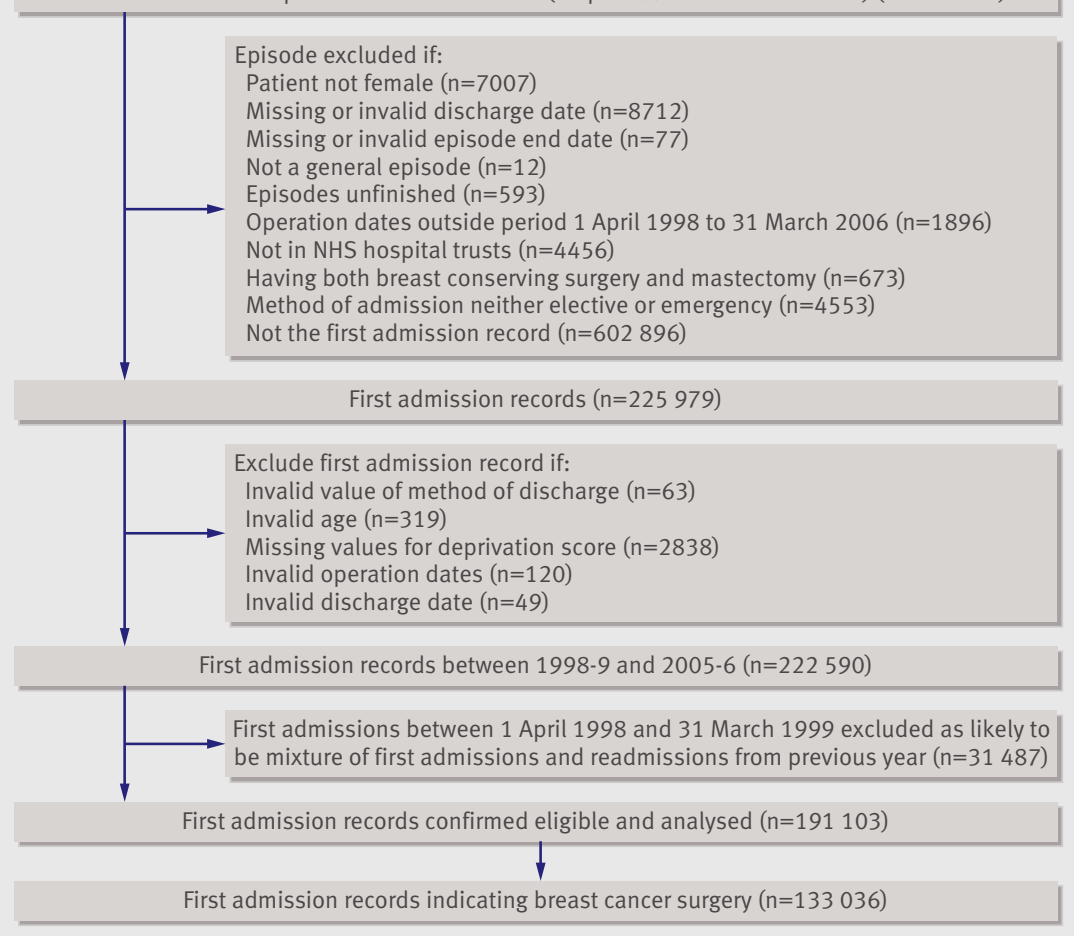

Fig 3 | Steps taken in selecting patients' records for analysis (breast cancer)

training deprivation," "barriers to housing and services," "living environment deprivation," and "crime." ${ }^{27}$ Each area is ranked relative to one another according to their level of deprivation.

\section{Study design}

We limited our analysis to patients aged 50 and over because over $90 \%$ of cancers are diagnosed in this age group. ${ }^{19} \mathrm{We}$ included all such patients admitted to NHS trusts (identified with the three digit provider code beginning with " $R$ ") initially between 1 April 1998 and 31 March 2006 with colorectal cancer (ICD-10 codes C18, C19, C20, C21) or lung cancer (ICD-10 codes C33, C34), and all women admitted with breast cancer (ICD-10 code C50) (based on 1st to 4 th diagnosis fields). To analyse variations in admission type, we identified the first elective or emergency admission record for each patient within the study period. Each admission period was defined as one year (from 1 April to 31 March for each year within the study). Because admission records from the first year in the dataset (1998-9) were likely to include a mixture of first and subsequent admissions, we excluded 19989 data from the analyses. Our results therefore cover the period 1 April 1999 to 31 March 2006. For the purposes of analysis, we coded year 1999-2000 as zero and 2005-6 as six.

We determined patients' age at admission by using the 15 th day of each month (in combination with year and month of birth) as an arbitrary birth date. We grouped age into 10 year increments from age 50 to age 90 and over. We examined patients' socioeconomic circumstances by dividing the deprivation ranks supplied by HES into fifths (where the lowest fifth referred to the most deprived).

Surgical procedures were identified (in up to 12 operation fields) with OPCS-4 codes. Thus we examined the probability of anterior resection (H33.2H33.6) compared with abdominoperineal resection (H33.1) for colorectal cancer code ICD-10 C20 because this is the code for rectal cancer. For breast cancer we examined the likelihood of receiving breast conserving surgery (B28) compared with mastectomy (B27). For lung cancer we examined the probability of surgical resection (E441, E54, E574, and E57.8).

We excluded records if they contained missing or invalid data for HES patient identifier, date of birth, sex, admission date, episode start date, episode end date, and discharge method. We also excluded records with surgical dates that either preceded the admission date or followed the discharge date.

\section{Analysis}

For each cancer, we first examined the distribution of emergency admissions by social group (age group, deprivation fifth, and sex for colorectal and lung cancer) and year of admission. We used multilevel logistic regression models with random intercepts (to allow for clustering within NHS trusts) to investigate univariable associations between mode of admission and sex, age group, socioeconomic circumstances, and admission period. We then fitted all the factors together in a multivariable model that also included interaction terms between admission year and every other factor. Interaction terms that were not significant at the 5\% significance level were omitted from the model. We used the interaction terms to determine if any associations between mode of admission and patients' sociodemographic characteristics were modified over time.

For each cancer, we then examined the distribution of defined surgical procedures by social group, admission type, and time period. We used multilevel logistic regression models with random intercepts to investigate univariable and multivariable associations between the odds of receiving defined surgical procedures and sex, age group, socioeconomic circumstances, admission type, and admission period. In the multivariable model, each factor was adjusted for all the other factors examined and interaction terms were included, as before, to determine if the associations between receipt of surgical procedure and social group and admission type were modified over time. We performed all analyses using the Stata 10.1 command xtmelogit (StataCorp, College Station, TX). Intraclass correlation coefficients were calculated with the method described by Snijders and Bosker. ${ }^{28}$

\section{RESULTS}

Between 1999 and 2006, 564821 patients aged 50 and over with colorectal, breast, or lung cancer were admitted (figs 1-4). 
Finished consultant episodes for lung cancer (1 April 1998 - 31 March 2006) ( $n=770$ 194)

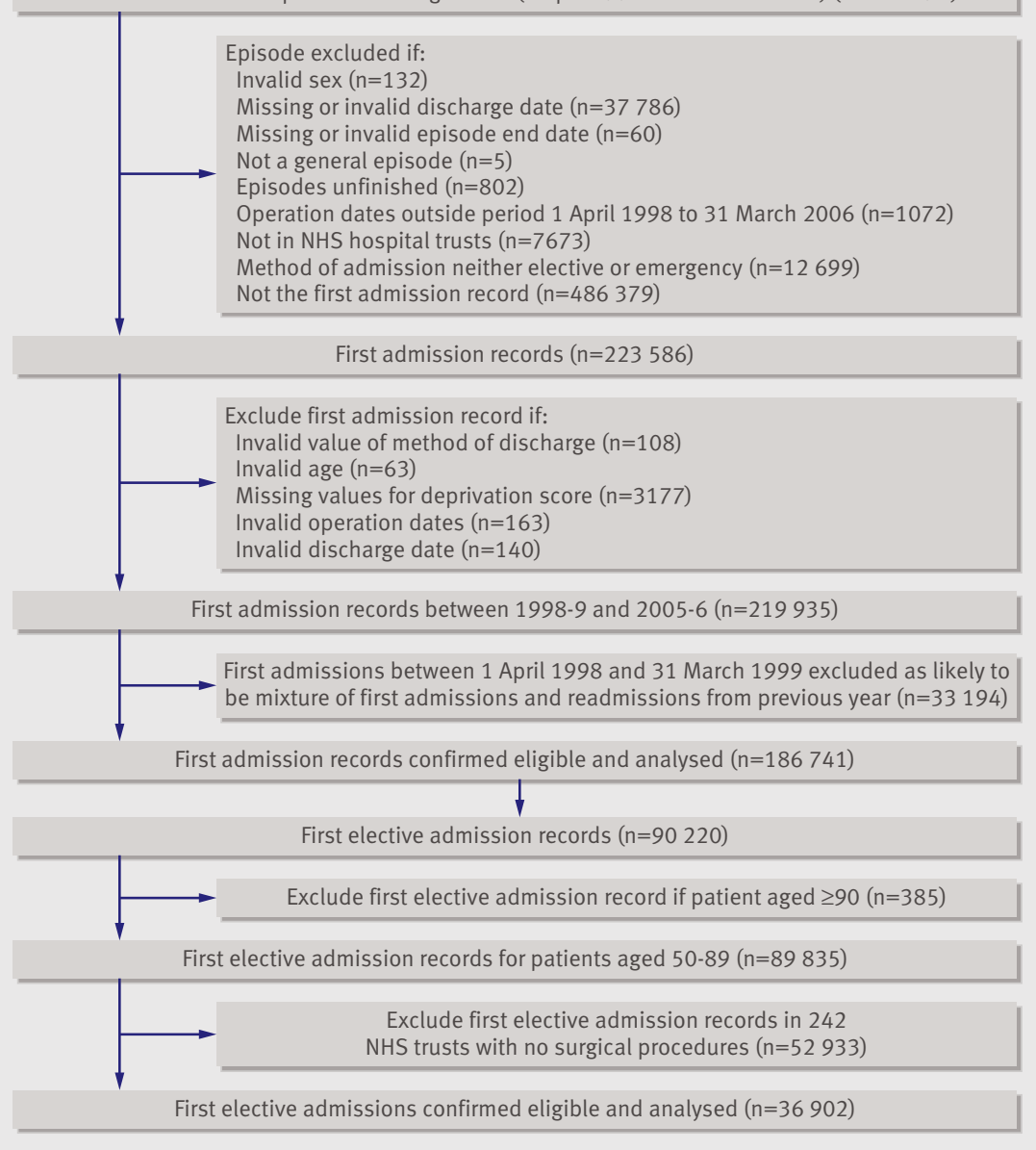

Fig 4 | Steps taken in selecting patients' records for analysis (lung cancer)

\section{Colorectal cancer}

During the period examined 186977 patients with colorectal cancer were admitted.

\section{Variation in type of admission by social factors and time period}

In $60684(32.5 \%)$ of first admissions, patients were admitted as emergencies. Table A on bmj.com shows the distribution of emergency admissions by sex, age group, deprivation fifth, and time period. Univariable analyses (table 1) indicate that emergency admissions were more common in women than men $(35.3 \%$ (29 751) v 30.1\% (30 933)) and were more likely with increasing age and deprivation. Thus $44.2 \%$ (18235) of patients aged 80-89 were admitted as emergencies compared with $24.4 \%$ (6102) of patients aged 50-59. Similarly, $37.9 \%$ (13026) of patients in the most deprived fifth of deprivation were emergency admissions compared with $28.9 \%(10689)$ of patients in the least deprived fifth.

In multivariable analyses (table 1), the effects of sex, age group, and deprivation on the odds of emergency admission persisted. The association with sex (odds ratio $1.15,95 \%$ confidence interval 1.12 to 1.17 ) remained stable over time. There was also a strong association with deprivation (for example, 0.66 (0.64 to 0.68 ) for emergency admission for patients in the least deprived fifth), which remained stable over time. The association with age, however, changed over time $(\mathrm{P}=0.01)$, with larger odds ratios at the start of the period (for example, for emergency admission for those aged 80-89 compared with those aged 50-59 the odds ratios were 2.53 (2.37 to 2.69 ) in 1999-2000 and 2.21 (2.07 to 2.35) in 2005-6). The proportion of emergency admissions decreased in older age groups but stayed relatively stable in younger groups.

\section{Variation in type of rectal surgery by social group,} admission type, and time period

Between 1999 and 2006, 29214 patients were admitted for rectal surgery, of whom 21014 (71.9\%) underwent anterior resection (see table B on bmj.com). There was an upward trend in the proportion of anterior resection from $69.8 \%$ (3318/4752) of rectal surgery in 1999-2000 to $73.5 \%$ (2920/3974) in 2005-6. Table B on bmj.com shows the distribution of anterior resection by social group, admission type, and time period. Univariable analyses (table 2) indicate that anterior resection was more common in women than in men $(73.6 \%$ (7807/ $10609) v 71.0 \%(13207 / 18605))$ and was more likely with increasing age and decreasing deprivation. Thus $73.7 \%(3161 / 4288)$ of patients aged $80-89$ had anterior resection compared with $70.1 \% \quad(3561 / 5080)$ of patients aged 50-59. Similarly, 67.4\% (3529/5237) of patients in the most deprived fifth had anterior resection compared with $75.5 \%(4497 / 5959)$ of patients in the least deprived fifth. In addition, patients admitted as an emergency were more likely to have anterior resection than those admitted electively $(82.8 \%$ (1193/1441) v 71.4\% (19 821/27 773)). These associations persisted in the multivariable model, though the association with age lessened slightly, and there was no evidence that these associations changed over timethat is, anterior resection was more common in patients admitted as emergencies (2.03, 1.76 to 2.34 ), and the trend to undertake anterior resection increased with time $(1.042,1.027$ to 1.056$)$. Anterior resection was also more common in women $(1.12,1.06$ to 1.18$)$ and in older patients. For example, the odds ratio for anterior resection in patients aged 80-89 compared with those aged 50-59 was 1.14 (1.04 to 1.25 ). There was also an association with decreasing deprivation (odds ratio for anterior resection for patients in the least deprived fifth $1.34,1.22$ to 1.47$)$.

\section{Breast cancer}

During the period under study 191103 women with breast cancer were admitted.

Variation in type of admission by social factors and time period

Over the seven year study period, 25244 (13.2\%) of first admissions were as emergencies. Table $\mathrm{C}$ on bmj.com shows the distribution of emergency admissions by age group, deprivation fifth, and time period. Univariable analyses (table 3) indicate that, in 
Table 1|Odds ratios (95\% confidence intervals) adjusted for clustering (186 977 patients in 304 providers) for emergency admission by social factors and admission period for patients with colorectal cancer (1 April 1999 to 31 March 2006)

\begin{tabular}{|c|c|c|c|c|c|c|}
\hline \multirow[b]{2}{*}{ Variable } & \multirow[b]{2}{*}{ Total* } & \multirow{2}{*}{$\begin{array}{c}\text { No (\%) of } \\
\text { emergency } \\
\text { admissions } †\end{array}$} & \multicolumn{2}{|c|}{ Univariable model } & \multicolumn{2}{|c|}{ Multivariable model $\ddagger$} \\
\hline & & & Odds ratio $(95 \% \mathrm{Cl})$ & P value $\S$ & Odds ratio $(95 \% \mathrm{Cl})$ & $P$ value§ \\
\hline Men & 102772 & $30933(30.1)$ & 1 & \multirow{2}{*}{$<0.001$} & 1 & \multirow{2}{*}{$<0.001$} \\
\hline Women & 84205 & $29751(35.3)$ & $1.27(1.25$ to 1.30$)$ & & 1.15 (1.12 to 1.17$)$ & \\
\hline \multicolumn{7}{|c|}{ Fifth of index of multiple deprivation: } \\
\hline 1 (most deprived) & 34404 & $13026(37.9)$ & 1 & \multirow{5}{*}{$<0.001$} & 1 & \multirow{5}{*}{$<0.001$} \\
\hline 2 & 36470 & $12522(34.3)$ & $0.84(0.81$ to 0.86$)$ & & $0.83(0.80$ to 0.86$)$ & \\
\hline 3 & 39309 & $12586(32.0)$ & $0.76(0.73$ to 0.78$)$ & & $0.75(0.72$ to 0.77$)$ & \\
\hline 4 & 39753 & $11861(29.8)$ & $0.68(0.66$ to 0.71$)$ & & $0.68(0.65$ to 0.70$)$ & \\
\hline 5 (least deprived) & 37041 & 10689 (28.9) & $0.66(0.63$ to 0.68$)$ & & 0.66 (0.64 to 0.68$)$ & \\
\hline \multicolumn{7}{|l|}{ Age group (years): } \\
\hline $50-59$ & 25002 & $6102(24.4)$ & 1 & \multirow{5}{*}{$<0.001$} & 1 & \multirow{5}{*}{$<0.001$} \\
\hline $60-69$ & 47149 & $11891(25.2)$ & 1.03 (1.00 to 1.07$)$ & & $1.05(0.98$ to 1.11$)$ & \\
\hline $70-79$ & 67625 & $20587(30.4)$ & $1.33(1.29$ to 1.38$)$ & & 1.41 (1.33 to 1.49$)$ & \\
\hline $80-89$ & 41299 & $18235(44.2)$ & $2.41(2.32$ to 2.49$)$ & & 2.53 (2.37 to 2.69$)$ & \\
\hline$\geq 90$ & 5902 & $3869(65.6)$ & $5.83(5.48$ to 6.20$)$ & & $5.85(5.23$ to 6.55$)$ & \\
\hline \multicolumn{7}{|c|}{ Admission period (reporting period 1 April to 31 March): } \\
\hline Per year & - & - & 0.985 (0.979 to 0.990$)$ & $<0.001$ & $0.996(0.982$ to 1.011$)$ & 0.595 \\
\hline \multicolumn{7}{|c|}{ Interaction between age group and admission period: } \\
\hline 50-59xperiod & - & - & - & - & 1 & \multirow{5}{*}{0.01} \\
\hline $60-69 \times$ period & - & - & - & - & $0.996(0.978$ to 1.014$)$ & \\
\hline 70-79xperiod & - & - & - & - & 0.979 (0.963 to 0.995$)$ & \\
\hline 80-89xperiod & - & - & - & - & $0.978(0.961$ to 0.995$)$ & \\
\hline$\geq 90 \times$ period & - & - & - & - & 0.989 (0.959 to 1.020$)$ & \\
\hline
\end{tabular}

*Figures based on first admission. Identification of patients with colorectal cancer based on 1st to 4th diagnosis fields.

†As percentage of total admissions.

łIntraclass correlation coefficient 0.026 (0.020 to 0.033 ).

$\S$ Wald tests of significance.

common with colorectal cancer, emergency admissions were more likely with increasing age and deprivation. For example, $17.0 \%$ (5315) of patients in the most deprived fifth were emergency admissions compared with $10.7 \%$ (4344) of patients in the least deprived fifth. Also, 34.8\% (8127) of patients aged 8089 were emergency admissions compared with just $5.5 \%$ (3542) of patients aged 50-59. In contrast with admissions for colorectal cancer, there was a significant downward trend in the proportion of patients who were admitted as emergencies. Total emergency admissions decreased from $16.1 \%$ (4588) of total admissions in 1999-2000 to $10.7 \%$ (3007) in 2005-6. In multivariable analyses (table 3 ) the effects of age group, deprivation, and admission period on the odds of emergency admission remained. In common with colorectal cancer, there was a strong association with deprivation (for example, the odds ratio for emergency admission for patients in the least deprived compared with most deprived fifth was $0.63,0.60$ to 0.66 ), which stayed stable over time. There was also a strong association with age group, but this changed over time $(\mathrm{P}<0.001)$. In particular, the odds ratios for the oldest age groups increased over time, reflecting the fact that the odds of emergency admission did not decrease as much for these patients as they did for the younger patients (for example, odds ratio for emergency admission for those aged 80-89 compared with 50-59 was 8.61 (7.97 to 9.29) in 1999-2000 and 9.83 (9.04 to $10.7)$ in $2005-6)$.

Variation in type of breast cancer surgery by social group, admission type, and time period

Of the 133036 patients with breast cancer admitted for surgery, $79740(59.9 \%)$ received breast conserving surgery (see table D on bmj.com). In common with anterior resection for rectal cancer, there was an upward trend in the proportion of breast conserving surgery from $58.9 \%$ (10 589/17 987) of breast cancer surgery in $1999-2000$ to $62.3 \%(13039 / 20913)$ in 2005-6. Table D on bmj.com shows the distribution of breast conserving surgery by social group, admission type, and time period. Univariable analyses (table 4) indicated that, in contrast with anterior resection, breast conserving surgery was more common in younger patients. Thus 48.1\% (14719/30577) of patients aged 70-79 had breast conserving surgery compared with 68.3\% (32113/47011) of patients aged 50-59. Breast conserving surgery was also less likely to be performed in patients admitted as emergencies (50.2\% (434/864) v 60.0\% (79306/132 172)). In common with anterior resection, there was an association between breast conserving surgery and decreasing deprivation: $54.0 \%(11256 / 20849)$ of patients in the 
Table 2 | Odds ratios (95\% confidence intervals) adjusted for clustering (29 214 patients in 215 providers) for anterior resection by social factors, admission type, and admission period for rectal cancer patients (1 April 1999 to 31 March 2006)

\begin{tabular}{|c|c|c|c|c|c|c|}
\hline \multirow[b]{2}{*}{ Variable } & \multirow[b]{2}{*}{ Total* } & \multirow{2}{*}{$\begin{array}{l}\text { No (\%) with anterior } \\
\text { resection† }\end{array}$} & \multicolumn{2}{|c|}{ Univariable model } & \multicolumn{2}{|c|}{ Multivariable model $\ddagger$} \\
\hline & & & Odds ratio $(95 \% \mathrm{Cl})$ & P value $\S$ & Odds ratio $(95 \% \mathrm{Cl})$ & Pvalue§ \\
\hline Men & 18605 & $13207(71.0)$ & 1 & $<0.001$ & 1 & $<0.001$ \\
\hline
\end{tabular}

Fifth of index of multiple deprivation:

\begin{tabular}{|c|c|c|c|c|c|c|}
\hline 1 (most deprived) & 5237 & $3529(67.4)$ & 1 & \multirow{4}{*}{$<0.001$} & 1 & \multirow{4}{*}{$<0.001$} \\
\hline 2 & 5610 & 3911 (69.7) & 1.12 (1.03 to 1.22$)$ & & 1.12 (1.03 to 1.22$)$ & \\
\hline 3 & 6155 & $4429(72.0)$ & $1.22(1.12$ to 1.33$)$ & & $1.23(1.12$ to 1.33$)$ & \\
\hline 5 (least deprived) & 5959 & $4497(75.5)$ & $1.33(1.21$ to 1.46$)$ & & 1.34 (1.22 to 1.47$)$ & \\
\hline
\end{tabular}

Age group (years):

\begin{tabular}{|c|c|c|c|c|c|c|}
\hline $50-59$ & 5080 & $3561(70.1)$ & 1 & \multirow{5}{*}{$<0.001$} & 1 & \multirow{5}{*}{0.010} \\
\hline $60-69$ & 9065 & $6491(71.6)$ & 1.08 (1.00 to 1.17$)$ & & 1.09 (1.01 to 1.17$)$ & \\
\hline $70-79$ & 10551 & $7618(72.2)$ & $1.10(1.02$ to 1.19$)$ & & $1.10(1.02$ to 1.19$)$ & \\
\hline $80-89$ & 4288 & 3161 (73.7) & 1.19 (1.08 to 1.30$)$ & & 1.14 (1.04 to 1.25$)$ & \\
\hline$\geq 90$ & 230 & $183(79.6)$ & 1.73 (1.24 to 2.41$)$ & & 1.52 (1.09 to 2.12$)$ & \\
\hline \multicolumn{7}{|c|}{ Admission type: } \\
\hline Elective & 27773 & $19821(71.4)$ & 1 & \multirow{2}{*}{$<0.001$} & 1 & \multirow{2}{*}{$<0.001$} \\
\hline Emergency & 1441 & $1193(82.8)$ & 2.02 (1.75 to 2.32$)$ & & 2.03 (1.76 to 2.34$)$ & \\
\hline \multicolumn{7}{|c|}{ Admission period (reporting period 1 April to 31 March): } \\
\hline Per year & - & - & 1.041 (1.026 to 1.055$)$ & $<0.001$ & $1.042(1.027$ to 1.056$)$ & $<0.001$ \\
\hline
\end{tabular}

*Figures based on first admission for patients with rectal cancer.

tAs percentage of total rectal surgery.

łIntraclass correlation coefficient 0.039 (0.030 to 0.051$)$.

$\S$ Wald tests of significance.

most deprived fifth had breast conserving surgery compared with $63.7 \%(18445 / 28960)$ of patients in the least deprived fifth. In multivariable analyses the effects of elective admission, age group, admission period, and deprivation on the odds of breast conserving surgery remained (table 4) - that is, breast conserving surgery was less common in patients admitted as emergencies $(0.81,0.70$ to 0.93$)$ and more common in patients from the least deprived fifth (for example, the odds ratio for breast conserving surgery for patients in the least deprived fifth was $1.21,1.16$ to 1.26$)$.

There was also evidence $(\mathrm{P}<0.001)$ that the association with age changed over time. This change seemed to be driven by the decreasing proportion of breast conserving surgery over time for those aged 80-89 compared with the other age groups, in which there was an increasing proportion of breast conserving surgery (for example, the odds ratio for receiving breast conserving surgery for those aged 80-89 compared with 50-59 was 0.42 (0.39 to 0.45$)$ in $1999-2000$ and 0.27 (0.25 to 0.29 ) in 2005-6).

\section{Lung cancer}

During the period examined 186741 patients with lung cancer were admitted.

Variation in type of admission by social factors and time period

A much higher proportion $(51.7 \% ; 96521)$ of patients with lung cancer were admitted as emergencies compared with patients with colorectal and breast cancer. Table $\mathrm{E}$ on bmj.com shows the distribution of emergency admissions by sex, age group, deprivation fifth, and admission period. Univariable analyses (table 5) show an increase in the proportion of patients admitted as emergencies over time. The proportion of emergency admissions increased from 49.8\% (14 219/ 28532 ) of total admissions in $1999-2000$ to $52.2 \%$ (13 948/26 702) in 2005-6. In common with colorectal cancer, emergency admissions were more common in women (53.5\% (39 396/73 575) v $50.5 \% \quad$ (57 125/ $113166)$ ) and, as with the other cancers studied, they were more likely with increasing age and deprivation. For example, $55.2 \%(28791 / 52181)$ of patients in the most deprived fifth were emergency admissions compared with $48.3 \%(12201 / 25249)$ of patients in the least deprived fifth. Also 69.1\% (22 772/32 948) of patients aged $80-89$ were emergency admissions compared with $39.6 \%$ (10 232/25 834) of patients aged 5059. In multivariable analyses (table 5), the effects of sex, age group, and deprivation on the odds of emergency admission persisted. Thus the odds ratio was 1.12 (1.09 to 1.14 ) for women and 0.64 (0.62 to 0.67 ) for patients in the least deprived fifth. These associations remained the same over time. There was also evidence that the association with age changed over time $(\mathrm{P}<0.001)$, perhaps driven by decreasing odds ratios for those aged 60-79 (for example, the odds ratio for emergency admission for those aged 60-69 compared with 50-59 was 1.23 (1.16 to 1.30) in 1999-2000 and 1.09 (1.03 to 1.15$)$ in 2005-6). 
Table 3|Odds ratios (95\% confidence intervals) adjusted for clustering (191 103 patients in 301 providers) for emergency admission by social factors and admission period for women with breast cancer (1 April 1999 to 31 March 2006)

\begin{tabular}{|c|c|c|c|c|c|c|}
\hline \multirow[b]{2}{*}{ Variable } & \multirow[b]{2}{*}{ Total $^{*}$} & \multirow{2}{*}{$\begin{array}{c}\text { No (\%) with emergency } \\
\text { admission† }\end{array}$} & \multicolumn{2}{|c|}{ Univariable model } & \multicolumn{2}{|c|}{ Multivariable model } \\
\hline & & & Odds ratio $(95 \% \mathrm{Cl})$ & P value $\S$ & Odds ratio $(95 \% \mathrm{Cl})$ & $P$ value \\
\hline \multicolumn{7}{|c|}{ Fifth of index of multiple deprivation: } \\
\hline 1 (most deprived) & 31236 & $5315(17.0)$ & 1 & \multirow{5}{*}{$<0.001$} & 1 & \multirow{5}{*}{$<0.001$} \\
\hline 2 & 35950 & $5256(14.6)$ & $0.82(0.78$ to 0.85$)$ & & $0.82(0.78$ to 0.86$)$ & \\
\hline 3 & 40966 & $5372(13.1)$ & $0.72(0.69$ to 0.76$)$ & & $0.74(0.71$ to 0.78$)$ & \\
\hline 4 & 42378 & $4957(11.7)$ & 0.65 (0.62 to 0.68$)$ & & 0.70 (0.66 to 0.73$)$ & \\
\hline 5 (least deprived) & 40573 & $4344(10.7)$ & 0.57 (0.54 to 0.59$)$ & & $0.63(0.60$ to 0.66$)$ & \\
\hline \multicolumn{7}{|l|}{ Age group (years): } \\
\hline $50-59$ & 64124 & $3542(5.5)$ & 1 & \multirow{5}{*}{$<0.001$} & 1 & \multirow{5}{*}{$<0.001$} \\
\hline $60-69$ & 55289 & $4080(7.4)$ & 1.36 (1.30 to 1.43$)$ & & 1.58 (1.47 to 1.71$)$ & \\
\hline $70-79$ & 44054 & $6832(15.5)$ & 3.09 (2.95 to 3.22$)$ & & 3.04 (2.82 to 3.27$)$ & \\
\hline $80-89$ & 23339 & $8127(34.8)$ & $9.23(8.82$ to 9.65$)$ & & 8.61 (7.97 to 9.29$)$ & \\
\hline$\geq 90$ & 4297 & $2663(62.0)$ & $28.83(26.82$ to 31.00$)$ & & 22.65 (19.89 to 25.80$)$ & \\
\hline \multicolumn{7}{|c|}{ Admission period (reporting period 1 April to 31 March): } \\
\hline Per year & - & - & 0.931 (0.925 to 0.938$)$ & $<0.001$ & 0.923 (0.907 to 0.939$)$ & $<0.001$ \\
\hline \multicolumn{7}{|c|}{ Interaction between age group and admission period: } \\
\hline $50-59 \times$ period & - & - & - & - & 1 & \multirow{5}{*}{$<0.001$} \\
\hline $60-69 \times$ period & - & - & - & - & 0.948 (0.926 to 0.971$)$ & \\
\hline 70-79×period & - & - & - & - & $1.002(0.981$ to 1.024$)$ & \\
\hline $80-89 \times$ period & - & - & - & - & $1.022(1.000$ to 1.045$)$ & \\
\hline$\geq 90 \times$ period & - & - & - & - & $1.083(1.045$ to 1.123$)$ & \\
\hline
\end{tabular}

*Figures based on first admission. Identification of breast cancer patients based on 1 st to 4th diagnosis fields.

†As percentage of total admissions.

‡ntraclass correlation coefficient 0.211 (0.175 to 0.251 ).

$\S$ Wald tests of significance.

Variation in lung cancer surgery by social group, admission type, and time period

There was a clear difference between the proportions of patients who received surgery subsequent to an elective admission $(9.7 \%, 8793)$ compared with an emergency admission $(0.1 \%, 130)$ (table F on bmj.com). As there were only 130 emergency admissions and just three patients aged 90 and above who underwent surgery, we conducted further analyses among elective patients aged less than 90 . Furthermore, lung cancer surgical resection was performed in just 38 trusts, and so we excluded 242 trusts where no surgery was performed. In those 38 trusts, $23.8 \%$ (8790) of patients underwent surgery in 1999-2006. Thus, table G on bmj.com and table 6 are limited to elective admissions for surgical resection in patients aged under 90 in those trusts that performed surgical resection (table $\mathrm{F}$ on bmj.com). Univariable analyses (table 6) show that, in contrast with the other surgical procedures studied, the likelihood of undergoing surgery for lung cancer did not increase over time. Such surgery was more likely to be performed in women $(26.2 \%$ (3731) $v$ $22.3 \%(5059))$ and in patients from the least deprived areas. Of patients in the least deprived fifth, $26.6 \%$ (1361) had surgery compared with $21.4 \%$ (2306) in the most deprived fifth. In common with breast conserving surgery, the likelihood of undergoing surgery for lung cancer diminished with increasing age $(13.5 \%$ (411) of patients aged 80-89 $v 23.8 \%$ (1669) of those aged 50-59). In multivariable analyses (table 6), the effects of sex, age group, and deprivation on the odds of lung cancer surgery persisted. Thus the odds ratio was 1.22 (1.16 to 1.29 ) for women and 1.63 (1.49 to 1.77) for patients in the least deprived fifth. There was also an association with increasing age (odds ratio for patients aged $80-89$ was $0.52,0.46$ to 0.59 ).

\section{DISCUSSION}

\section{Main findings}

In this national study of over 560000 patients aged 50 and over, we found mixed evidence for improvements over time in the mode of admission and in the odds of preferred surgical treatment for the three most common cancers. We also found that social factors including deprivation and age still strongly influence access to and the provision of care. Nearly a third of patients with colorectal cancer were admitted as emergencies, and this proportion did not improve over time. For breast cancer, there was downward trend in the proportion of patients who were admitted as emergencies between 1999 and 2006. Over half of patients with lung cancer were admitted as emergencies, and this proportion increased over time. Less than $10 \%$ of elective patients with lung cancer underwent resection, and there was no improvement overall in their likelihood of receiving surgery over time. In the 38 trusts where resection for lung cancer was performed, however, the rate of resection was $23.8 \%$. 
Table $4 \mid$ Odds ratio (95\% confidence intervals) adjusted for clustering (133 036 patients in 219 providers) for breast conserving surgery and social factors, admission type, and admission period for women admitted with breast cancer (1 April 1999 to 31 March 2006)

\begin{tabular}{|c|c|c|c|c|c|c|}
\hline \multirow[b]{2}{*}{ Variable } & \multirow[b]{2}{*}{ Total* } & \multirow{2}{*}{$\begin{array}{l}\text { No (\%) with breast } \\
\text { conserving surgery } \dagger\end{array}$} & \multicolumn{2}{|c|}{ Univariable model } & \multicolumn{2}{|c|}{ Multivariable model $\ddagger$} \\
\hline & & & Odds ratio $(95 \% \mathrm{Cl})$ & $P$ value§ & Odds ratio $(95 \% \mathrm{Cl})$ & P value \\
\hline \multicolumn{7}{|c|}{ Fifth of index of multiple deprivation: } \\
\hline 1 (most deprived) & 20849 & $11256(54.0)$ & 1 & \multirow{5}{*}{$<0.001$} & 1 & \multirow{5}{*}{$<0.001$} \\
\hline 2 & 24608 & $14383(58.4)$ & $1.10(1.05$ to 1.14$)$ & & 1.09 (1.05 to 1.13$)$ & \\
\hline 3 & 28582 & $17099(59.8)$ & 1.12 (1.08 to 1.17$)$ & & $1.10(1.06$ to 1.15$)$ & \\
\hline 4 & 30037 & $18557(61.8)$ & 1.22 (1.18 to 1.27$)$ & & 1.19 (1.14 to 1.24$)$ & \\
\hline 5 (least deprived) & 28960 & $18445(63.7)$ & 1.25 (1.20 to 1.30$)$ & & 1.21 (1.16 to 1.26$)$ & \\
\hline \multicolumn{7}{|l|}{ Age group (years): } \\
\hline $50-59$ & 47011 & $32113(68.3)$ & 1 & \multirow{5}{*}{$<0.001$} & 1 & \multirow{5}{*}{$<0.001$} \\
\hline $60-69$ & 42026 & $27076(64.4)$ & 0.83 (0.81 to 0.86$)$ & & $0.76(0.72$ to 0.80$)$ & \\
\hline $70-79$ & 30577 & $14719(48.1)$ & $0.42(0.41$ to 0.43$)$ & & $0.43(0.41$ to 0.45$)$ & \\
\hline $80-89$ & 12220 & $5262(43.1)$ & $0.33(0.32$ to 0.35$)$ & & $0.42(0.39$ to 0.45$)$ & \\
\hline$\geq 90$ & 1202 & $570(47.4)$ & $0.39(0.34$ to 0.43$)$ & & $0.44(0.34$ to 0.52$)$ & \\
\hline \multicolumn{7}{|l|}{ Admission type: } \\
\hline Elective & 132172 & $79306(60.0)$ & 1 & \multirow{2}{*}{$<0.001$} & 1 & \multirow{2}{*}{0.004} \\
\hline Emergency & 864 & $434(50.2)$ & 0.68 (0.60 to 0.78$)$ & & 0.81 (0.70 to 0.93$)$ & \\
\hline \multicolumn{7}{|c|}{ Admission period (reporting period 1 April to $31 \mathrm{March}$ ): } \\
\hline Per year & - & 一 & $1.028(1.021$ to 1.034$)$ & $<0.001$ & 1.027 (1.017 to 1.038$)$ & $<0.001$ \\
\hline \multicolumn{7}{|c|}{ Interaction between age group and admission period: } \\
\hline $50-59 \times$ period & - & - & - & - & 1 & \multirow{5}{*}{$<0.001$} \\
\hline 60-69×period & - & 一 & 一 & - & $1.027(1.012$ to 1.042$)$ & \\
\hline 70-79xperiod & - & 一 & - & - & $0.992(0.977$ to 1.007$)$ & \\
\hline 80-89xperiod & - & - & - & - & $0.930(0.911$ to 0.950$)$ & \\
\hline$\geq 90 \times$ period & - & - & - & - & 0.973 (0.917 to 1.031$)$ & \\
\hline
\end{tabular}

*Figures based on first admission for breast cancer patients.

†As percentage of total breast cancer surgery.

łIntraclass correlation coefficient 0.065 (0.054 to 0.080).

$\S$ Wald tests of significance.

Patients from deprived areas were more likely to be admitted as emergencies and were less likely to receive anterior resection, breast conserving surgery, and resection for lung cancer. These findings did not improve over time. Women were also more likely than men to be admitted as emergencies. In terms of preferred surgical treatment, men were slightly less likely to undergo anterior resection and resection for lung cancer.

Older patients were also more likely to be admitted as emergencies. There were some improvements over time in disparities between age groups for patients with colorectal cancer. Although older people were more likely to undergo anterior resection, they were less likely to undergo breast conserving surgery and lung cancer resection. There were few changes over time.

\section{Methodological strengths and limitations}

By using the hospital episode statistics dataset, we were able to examine pathways to care and receipt of surgical interventions for every patient admitted to an NHS hospital in England with colorectal, breast, or lung cancer in 1999-2006. We were therefore able to present a national picture of key trends with respect to cancer care associated with national reforms in NHS cancer services.
Our study, however, shares the limitations of all research that uses routinely collected data with respect to the completeness and accuracy of data coding. In recognition of these, we used the first three characters of ICD-10 codes for diagnoses (together with the OPCS-4 codes for procedures) because these are known to be more reliable than the full clinical codes. ${ }^{29}$ In addition, our analysis was at national rather than at trust level. A comparison of hospital episode statistics data with those from a national colorectal cancer database found that agreement between reported caseload and operative mortality was better at national than at hospital level and that the closest agreement between datasets occurred for the two procedures that we compared: anterior resection and abdominoperineal resection. ${ }^{30}$ Finally, despite the recognised issues with the quality of hospital episode statistics data, there is no reason to assume that completeness and accuracy of the data should be correlated with deprivation status, sex, or age of patients.

We attempted to restrict our analysis to first admissions by removing the earliest year of our dataset (1998-9) from our analyses. We checked the assumption that it was sufficient to remove one year of data by identifying the number of patients first admitted in 2003-4 who were readmitted in 2004-5 (within one 
Table 5|Odds ratios (95\% confidence intervals) adjusted for clustering (186 741 patients in 311 providers) for emergency admission by social factors and admission period for patients with lung cancer (1 April 1999 - 31 March 2006)

\begin{tabular}{|c|c|c|c|c|c|c|}
\hline \multirow[b]{2}{*}{ Variable } & \multirow[b]{2}{*}{ Total* } & \multirow{2}{*}{$\begin{array}{l}\text { No (\%) with } \\
\text { emergency } \\
\text { admission† }\end{array}$} & \multicolumn{2}{|c|}{ Univariable model } & \multicolumn{2}{|c|}{ Multivariable model $\ddagger$} \\
\hline & & & Odds ratio $(95 \% \mathrm{Cl})$ & P value§ & Odds ratio $(95 \% \mathrm{Cl})$ & P value $\S$ \\
\hline Men & 113166 & $57125(50.5)$ & 1 & \multirow{2}{*}{$<0.001$} & 1 & \multirow{2}{*}{$<0.001$} \\
\hline Women & 73575 & $39396(53.5)$ & 1.14 (1.11 to 1.16$)$ & & 1.12 (1.09 to 1.14$)$ & \\
\hline \multicolumn{7}{|c|}{ Fifth of index of multiple deprivation: } \\
\hline 1 (most deprived) & 52181 & $28791(55.2)$ & 1 & \multirow{5}{*}{$<0.001$} & 1 & \multirow{5}{*}{$<0.001$} \\
\hline 2 & 41593 & $21662(52.1)$ & $0.82(0.79$ to 0.84$)$ & & 0.80 (0.78 to 0.82$)$ & \\
\hline 3 & 36153 & $18354(50.8)$ & 0.77 (0.74 to 0.79$)$ & & $0.74(0.72$ to 0.76$)$ & \\
\hline 4 & 31565 & $15513(49.1)$ & $0.72(0.69$ to 0.74$)$ & & $0.68(0.66$ to 0.71$)$ & \\
\hline 5 (least deprived) & 25249 & $12201(48.3)$ & $0.68(0.65$ to 0.70$)$ & & 0.64 (0.62 to 0.67$)$ & \\
\hline \multicolumn{7}{|l|}{ Age group (years): } \\
\hline $50-59$ & 25834 & $10232(39.6)$ & 1 & \multirow{5}{*}{$<0.001$} & 1 & \multirow{5}{*}{$<0.001$} \\
\hline $60-69$ & 51898 & $22535(43.4)$ & 1.15 (1.12 to 1.19$)$ & & $1.23(1.16$ to 1.30$)$ & \\
\hline $70-79$ & 72801 & $38107(52.3)$ & 1.62 (1.57 to 1.67$)$ & & 1.70 (1.61 to 1.80$)$ & \\
\hline $80-89$ & 32948 & $22772(69.1)$ & 3.20 (3.09 to 3.32$)$ & & $3.13(2.93$ to 3.34$)$ & \\
\hline$\geq 90$ & 3260 & $2875(88.2)$ & $10.61(9.49$ to 11.88$)$ & & $11.03(8.93$ to 13.62$)$ & \\
\hline \multicolumn{7}{|c|}{ Admission period (reporting period 1 April to 31 March): } \\
\hline Per year & - & - & $1.018(1.013$ to 1.024$)$ & $<0.001$ & $1.021(1.008$ to 1.035$)$ & 0.002 \\
\hline \multicolumn{7}{|c|}{ Interaction between age group and admission period: } \\
\hline 50-59xperiod & - & - & - & - & 1 & \multirow{5}{*}{$<0.001$} \\
\hline 60-69 xperiod & - & - & - & - & $0.980(0.965$ to 0.996$)$ & \\
\hline 70-79xperiod & - & - & - & - & $0.987(0.972$ to 1.002$)$ & \\
\hline 80-89xperiod & - & - & - & - & 1.011 (0.993 to 1.029$)$ & \\
\hline$\geq 90 \times$ period & - & - & - & - & $0.993(0.938$ to 1.050$)$ & \\
\hline
\end{tabular}

*Figures based on first admission. Identification of lung cancer patients based on 1st to 4th diagnosis fields.

†As percentage of total admissions.

†Intraclass correlation coefficient 0.217 (0.184 to 0.254 ).

§Wald tests of significance.

year) or in 2005-6 (within two years). The numbers of subsequent admissions within two years was small at $4 \%$ for breast cancer, $5 \%$ for lung cancer, and $7 \%$ for colorectal cancer, whereas within one year it was $15 \%$ for breast cancer, 20\% for lung cancer, and 24\% for colorectal cancer. Therefore it seemed reasonable to restrict exclusion of data to the first year (1998-9) only. An alternative way to analyse these data would have been to use a "moving window," with all admissions excluded if there was an earlier admission in the window period. The necessary size of the window, however, is uncertain: too long and it inhibits analysis of trends in these data; too short and there is a danger that patients might be admitted outside that window, which would result in them appearing in the dataset more than once.

We used the index of multiple deprivation, a well established method of assigning socioeconomic characteristics based on area of residence. This method rests on the assumption that individuals conform to the socioeconomic profile of their residential area We recognise that misclassifications of individuals' socioeconomic circumstances can cause under- or overestimates of the relation between socioeconomic circumstances and admission type/procedure use. We used the version published in 2004 because this was the most recent available at the time that the data were acquired.
Most of the indicators used in the construction of the 2004 deprivation index relate to 2001. This raises the question of the extent to which the relative deprivation of an area in 2001 reflects that in 1999 and in 2006. The research group who developed the deprivation scores $^{27}$ compared relative deprivation as reported with the deprivation measure published in 2000 (based on 1998 data) and that published in 2004 (based on 2001 data) and found a marked degree of similarity between the relative positions of local authorities. Furthermore, the impact of any real change in deprivation has been attenuated in our analyses by the use of deprivation fifths. Thus when we cross tabulated the 2004 and 2007 data to assess level of change in fifths, we found that $81 \%$ of lower super output areas remained in the same fifth, with just $1 \%$ moving up or down by more than one fifth. Finally we repeated the analyses using the 2007 index and compared the multivariable associations between mode of admission/procedure use and socioeconomic characteristics as defined by the 2004 and 2007 indices. We found negligible differences in the results obtained (data not shown).

A major limitation of our study was the lack of information on tumour stage, other characteristics of the tumour, case mix, and patients' preferences. While these are potential confounders, it is difficult to predict their effect on our results because evidence on the 
Table 6 | Odds ratios (95\% confidence intervals) adjusted for clustering (36 902 patients in 38 providers) for lung cancer surgery by social factors, for electively admitted patients with lung cancer (admissions 1 April 1999 to 31 March 2006)

\begin{tabular}{|c|c|c|c|c|c|c|}
\hline \multirow[b]{2}{*}{ Variable } & \multirow[b]{2}{*}{ Total* } & \multirow{2}{*}{$\begin{array}{l}\text { No undergoing } \\
\text { surgery (\%†) }\end{array}$} & \multicolumn{2}{|c|}{ Univariable model } & \multicolumn{2}{|c|}{ Multivariable model } \\
\hline & & & OR $(95 \% \mathrm{Cl})$ & P value & OR $(95 \% \mathrm{CI})$ & P value§ \\
\hline Men & 22664 & $5059(22.3)$ & 1 & \multirow{2}{*}{$<0.001$} & 1 & \multirow{2}{*}{$<0.001$} \\
\hline Women & 14238 & $3731(26.2)$ & 1.22 (1.16 to 1.28$)$ & & 1.22 (1.16 to 1.29$)$ & \\
\hline
\end{tabular}

Fifth of index of multiple deprivation:

\begin{tabular}{|c|c|c|c|c|c|c|}
\hline 1 (most deprived) & 10789 & $2306(21.4)$ & 1 & \multirow{5}{*}{$<0.001$} & 1 & \multirow{5}{*}{$<0.001$} \\
\hline 2 & 7829 & $1810(23.1)$ & $1.33(1.24$ to 1.44$)$ & & 1.34 (1.25 to 1.45$)$ & \\
\hline 3 & 6917 & $1703(24.6)$ & 1.44 (1.33 to 1.55$)$ & & 1.45 (1.35 to 1.57$)$ & \\
\hline 4 & 6251 & $1610(25.8)$ & $1.56(1.44$ to 1.69$)$ & & 1.58 (1.46 to 1.72$)$ & \\
\hline 5 (least deprived) & 5116 & $1361(26.6)$ & 1.60 (1.47 to 1.74$)$ & & 1.63 (1.49 to 1.77$)$ & \\
\hline
\end{tabular}

Age group (years):

\begin{tabular}{|c|c|c|c|c|c|c|}
\hline $50-59$ & 7008 & 1669 (23.8) & 1 & \multirow{4}{*}{$<0.001$} & 1 & \multirow{4}{*}{$<0.001$} \\
\hline $60-69$ & 12868 & $3286(25.5)$ & 1.09 (1.02 to 1.17$)$ & & 1.11 (1.04 to 1.19$)$ & \\
\hline $70-79$ & 13975 & 3424 (24.5) & 1.05 (0.98 to 1.13$)$ & & $1.06(0.99$ to 1.14$)$ & \\
\hline $80-89$ & 3051 & $411(13.5)$ & 0.52 (0.46 to 0.59$)$ & & 0.52 (0.46 to 0.59$)$ & \\
\hline
\end{tabular}

Admission period (reporting period 1 April to 31 March):

$\begin{array}{lllllll}\text { Per year } & - & - & & 1.000(0.987 \text { to } 1.013) & 0.994 & 1.002 \text { (0.989 to } 1.015)\end{array}$

*Figures based upon first elective admission for lung cancer patients within NHS trusts performing at least one surgical procedure.

†As percentage of total admissions.

łntraclass correlation coefficient 0.140 (0.091 to 0.208).

$\S$ Wald tests of significance.

associations between certain factors - such as tumour stage and socioeconomic circumstances-is inconsistent. ${ }^{31-34}$ Given the lack of this information in the hospital episode statistics dataset, we cannot ascertain the extent to which differences in the likelihood of surgery reflected clinical characteristics at presentation or inequalities in treatment. For lung cancer, surgical resection is recommended only for patients with stage I or II non-small cell lung cancer. ${ }^{14}$ For rectal cancer, the choice of operation depends on the distance of the tumour from the anal verge,${ }^{26}$ and patients need to consider the benefits of avoiding a permanent stoma versus the potential risks of faecal urgency. For breast cancer, trials have shown no survival advantage for mastectomy over breast conserving surgery for tumours up to $5 \mathrm{~cm} .{ }^{35}$ Mastectomy, however, is recommended for multi-focal tumours, when the tumour is directly behind the nipple, or for a large tumour in a small breast, which would produce an unacceptable cosmetic result. ${ }^{36}$ Some women also choose mastectomy over breast conserving surgery. ${ }^{37}$ The determinants of such choices, including expectations for good health and perceptions of risks and benefits associated with defined interventions, are themselves socially patterned. ${ }^{38}$

If we had had accurate data on pre-operative comorbidity and its severity, adjustment for comorbidity might have diluted the associations found. Such an adjustment would probably have more of an effect on admission route than on receipt of surgery because comorbidity is likely to delay surgery (within the same admission) rather than to prevent it. Adjustment for the number of comorbidities (defined as the number of conditions listed in the 1st to 4 th diagnosis fields) in the multivariable models marginally diluted the associations found (data not shown).
Finally, we assumed that the impact of inequalitiesthat is, the associations between the outcomes and the socioeconomic factors - was the same across all trusts. Multilevel models with random intercepts were used, and these suggested a moderate degree of heterogeneity between trusts particularly with respect to the mode of admission for breast cancer and lung cancer (intraclass correlation coefficients of 0.21 and 0.22 , respectively). For trusts with over 100 admissions in total, emergency admission rates for breast cancer were generally between $5 \%$ and $50 \%$ and for lung cancer were generally between $9 \%$ and $93 \%$. The intraclass correlation coefficient for the lung cancer resection analysis was also moderate $(0.14)$, with resection rates between $1 \%$ and $53 \%$.

\section{Comparison with other studies}

Differences in emergency admission rates among social groups might reflect either social variations in mode of admission (emergency versus elective) or social differences in the likelihood of being admitted at all. Comparisons of social variations in incidence of cancer in the population with social variations in total admissions for cancer suggest that our results reflect the first explanation. For example, the sex ratio in admissions for lung cancer is similar to the sex ratio in the incidence of lung cancer ${ }^{39}$; for breast cancer, ratios of incidence and of total admissions in the least deprived compared with the most deprived groups are also similar. ${ }^{40}$

Research conducted just before the reorganisation of cancer services found that patients from deprived areas with colorectal, breast, or lung cancer were more likely to be admitted as emergencies than their counterparts from more affluent areas. ${ }^{4}$ More recent research on rectal and lung cancer accords with our findings of 
continuing associations between deprivation and emergency admission for rectal cancer and also reports a high proportion of patients with lung cancer being admitted as emergencies. ${ }^{22641}$

Other studies have found social variations in procedure use, which also mirror our results. We replicated and updated two studies of rectal surgery up to 2004, which found decreasing rates of abdominoperineal resection over time and a strong trend in relation to socioeconomic status and anterior resection, which remained after adjustment for staging differences. ${ }^{2642}$ In common with our study, the potential influence of comorbidity on this association was not examined. The age gradient in provision of anterior resection found in our study, however, was no longer present once stage at diagnosis and annual median surgical workload were taken into account (in addition to the explanatory variables included in our analysis). The association between emergency admission and anterior resection found in our research and that of others does not imply that these procedures were performed as emergencies but that the patients presented initially as emergencies. Over the past decade, patients admitted as emergencies have increasingly been provided with a colonic stent and re-admitted for elective anterior resection at a later date. ${ }^{26}$ The higher abdominoperineal resection rates in men might be a function of the male pelvic anatomy and difficulties in achieving a safe low rectal dissection. ${ }^{2642}$

The proportion of women undergoing breast conserving surgery in our national analysis reflected that reported from one regional analysis ${ }^{9}$ but was higher than figures reported from other areas in the UK. ${ }^{434}$ These regional studies noted variations in breast conserving surgery across cancer teams. ${ }^{944}$ This might either reflect clinical uncertainty, despite the presence of guidelines, or the complex interaction between tumour characteristics, the information presented to patients, and their evaluations of the risks and benefits involved. ${ }^{34}$ Thus our observation that older women were less likely to undergo breast conserving surgery might be explained by their attitudes to body image and concerns about safety. ${ }^{456}$ Other research found that women from deprived areas were more likely to have a mastectomy than women from more affluent areas. ${ }^{44}$ This might be because women from deprived areas have larger and symptomatic tumours. ${ }^{44}$

Other studies reported a lung cancer surgical resection rate of $7-10 \%$, which is similar to our findings for elective admissions. ${ }^{64147}$ There was, however, wide variation across cancer networks, from below $5 \%$ to above $15 \%$. $^{2241}$ When we restricted our analyses to those trusts that performed lung cancer resection, we found an average surgical resection rate of $23.8 \%$, which is comparable with the upper limit found in other European countries where rates of 17.5-25\% have been reported. ${ }^{47-49}$ A comparison of the management of lung cancer in Italy and England suggested that the lower rates in England might partly be a result of English patients presenting at a later stage, with more aggressive types of tumour and with higher comorbidity. ${ }^{47}$ Moreover, improvements in the efficient and systematic management of suspicious lesions in the UK has also led to higher resection rates. ${ }^{5051}$

The proportion of trusts in the HES dataset (that we analysed) with records of surgical lung resection was far lower than that reported in a more recent lung cancer audit $\left(18 \%\right.$ v 87\%). ${ }^{41}$ We therefore examined procedure use for those trusts where HES recorded that no surgery had been performed but where the audit recorded that surgery had occurred. We found that procedures such as biopsies, aspirations, and insertion of tube drains had been performed in these trusts and if these were included as surgery in the audit then this would explain the difference in our results. Variations in the completeness of recording of surgical procedures in HES might also, in part, explain the differences between the datasets.

Finally, our findings reflect other research showing that among patients with lung cancer, older patients and men were less likely to undergo surgery and people living in deprived areas were less likely to receive anti-cancer treatment. ${ }^{75253}$

The variation identified between trusts is likely to be secondary to the case mix of patients and to variations in the organisation of services and implementation of standards by trusts. ${ }^{54}$

\section{Implications and conclusions}

During the 1990s socioeconomic inequalities in survival widened for colorectal cancer and did not improve for lung and breast cancer. ${ }^{55}$ Women have better five year survival than men for lung cancer and younger patients with cancer have better five year survival than older patients. ${ }^{56}$ Reducing inequalities in survival depends on improving timely presentation, early referral, and the application of evidence based clinical guidelines among socially disadvantaged groups. ${ }^{5758}$ National patient reported data ${ }^{59}$ suggest that female patients with colorectal cancer had diagnostic delays in referral from primary care but that such delays are unlikely to explain the higher likelihood of emergency admissions among patients from deprived areas and older patients. A recent analysis of national hospital activity data showed that in 1997 (just two years before the start date for our analysis) the greater the degree of deprivation, the longer the waiting time from referral to surgery (for non-oncological conditions). But by 2007, the relation was less pronounced. ${ }^{60}$ These findings suggest that both social variations in timely presentation and in pathways to care need to be prospectively examined to clarify the extent to which targeted symptom awareness raising campaigns and improved access to and referral from primary care are required. In addition adherence to cancer standards varies widely between cancer networks. ${ }^{54}$ Audit of local surgical practice and monitoring of sociodemographic variations in procedure use are also recommended to raise standards and ensure best practice. $^{1754}$ 


\section{What is already known on this topic}

The NHS Cancer Plan was published in 2000 to improve outcomes overall and to reduce health inequalities, in part through greater equity of access to and provision of health care for all social groups

The extent to which access to health care has improved for all those in need regardless of their socioeconomic circumstances, age, or sex has not been examined

What this study adds

From 1999 to 2006, nearly a third of patients with colorectal cancer were admitted as emergencies, and this proportion did not improve over time; there was downward trend in the proportion of patients with breast cancer admitted as emergencies; over half of patients with lung cancer were admitted as emergencies, and this proportion increased over time

Patients from deprived areas, older people, and women continue to be more likely to be admitted as emergencies

Less than $10 \%$ of elective patients with lung cancer underwent surgical resection, and there was no improvement overall in their likelihood of receiving surgery over time Living in deprived areas and being male were associated with lower likelihood of receiving preferred surgical procedures for these cancers; older people were more likely to receive the preferred surgical procedure for rectal cancer but less likely to receive breast conserving surgery and lung cancer resection
8 Morris E, Haward R, Gilthorpe M, Craigs C, Forman D. The impact of the Calman-Hine report on the processes and outcomes of care for Yorkshire's colorectal cancer patients. Br / Cancer 2006;95:979-85.

9 Morris E, Haward R, Gilthorpe M, Craigs C, Forman D. The impact of the Calman-Hine report on the processes and outcomes of care for Yorkshire's breast cancer patients. Ann Oncol 2008;19:284-91.

10 Department of Health. The NHS cancer plan: a plan for investment, a plan for reform. 2000. www.dh.gov.uk/en/ Publicationsandstatistics/Publications/

PublicationsPolicyAndGuidance/DH 4009609.

11 Richards M. Assessment of the NHS cancer plan in England. Lancet Oncol 2009;10:311.

12 National Institute for Health and Clinical Excellence. Guidance on cancer services: improving outcomes in breast cancer-manual update. 2002. http://webcat.hud.ac.uk/ipac20/ipac.jsp? full=3100001 !418963 !0\&profile=cls.

13 National Institute for Health and Clinical Excellence. Guidance on cancer services: improving outcomes in colorectal cancer-manual update. 2004. www.nice.org.uk/nicemedia/pdf/ CSGCCfullguidance.pdf.

14 National Institute for Health and Clinical Excellence. Lung cancer: the diagnosis and treatment of lung cancer. 2005. www.nice.org.uk/ nicemedia/pdf/CG024niceguideline.pdf.

15 National Audit Office. The NHS cancer plan: a progress report. 2005. www.nao.org.uk/publications/0405/the_nhs_cancer_plan.aspx? alreadysearchfor=yes.

16 Department of Health. The NHS cancer plan: three-year progress report-maintaining the momentum. 2003. www.dh.gov.uk/en/ Publicationsandstatistics/Publications/ PublicationsPolicyAndGuidance/DH 4066438.

17 Rachet B, Maringe C, Nur U, Quaresma M, Shah A, Woods L, et al. Population based cancer survival trends in England and Wales up to 2007: an assessment of the NHS cancer plan for England. Lancet Oncol 2009;10:351-69.

We thank Richard Morris, Madhavi Bajekal, and the reviewers for their valuable comments.

Contributors: RR had the idea for the research, led the study, and is guarantor. RR and GA collaborated on the study design and interpretation of results. CA contributed to the study design. GA led the statistical analysis. WW and SS undertook the analysis. AO provided expert clinical advice. All authors contributed and commented on drafts of the article and approved the final version.

Funding: RR is partly funded by a National Institute for Health Research public health career scientist award and by the National Institute for Health Research University College London Hospital/University College London Comprehensive Biomedical Research Centre. WW and SS are funded by Legal and General Group. AO is partly funded by CRUK. The research was funded in part by the actuarial profession (Institute of Actuaries in England and Wales and the Faculty of Actuaries in Scotland). The authors' work was independent of the funders.

Competing interests: None declared.

Ethical approval: This study was approved by the Information Governance, Information Centre for Health and Social Care (reference No ET1366).

Data sharing: No additional data available.

1 Berrino F, De Angelis R, Sant M, Rosso S, Bielska-Lasota M, Coebergh J, et al. Survival for eight major cancers and all cancers combined for European adults diagnosed in 1995-99: results of the EUROCARE-4 study. Lancet Oncol 2007;8:773-83.

2 Janssen-Heijnen M, Gatta G, Forman D, Capocaccia R, Coebergh I, EUROCARE Working Group. Variation in survival of patients with lung cancer in Europe 1985-1989. Eur J Cancer 1998;34:2191-6.

3 Sant M, Aareleid T, Berrino F, Bielska Lasota M, Carli PM, Faivre J, et al. EUROCARE-3: survival of cancer patients diagnosed 1990-94results and commentary. Ann Oncol 2003;14(suppl 5):n61-71S

4 Pollock A, Vickers N. Deprivation and emergency admissions for cancers of colorectum, lung, and breast in south east England: ecological study. BMJ 1998;317:245-52.

5 Department of Health. A policy framework for commissioning cancer services: a report by the expert advisory group on cancer to the chie medical officers of England and Wales (the Calman Hine report). 1995. www.dh.gov.uk/en/Publicationsandstatistics/Publications/ PublicationsPolicyAndGuidance/DH 4071083.

6 Battersby J, Flowers J, Harvey I. An alternative approach to quantifying and addressing inequity in healthcare provision: access to surgery for lung cancer in East England. J Epidemiol Community Health 2004;58:623-5.

7 Jack R, Gulliford M, Ferguson J, Møller H. Geographical inequalities in lung cancer management and survival in South East England: evidence of variation in access to oncology services? Br J Cancer 2003;88:1025-31.

18 Gulliford M, Morgan M, eds. Access to health care. Routledge, 2003.

19 Office for National Statistics. Cancer statistics registrations. 2008. www.statistics.gov.uk/downloads/theme_health/MB1-37/ MB1_37_2006.pdf, 2008.

20 Office for National Statistics. Mortality statistics-deaths registered in 2007. 2008. www.statistics.gov.uk/downloads/theme health/ DR2007/DR_07_2007.pdf.

21 Department of Health. Guidance on commissioning cancer services: improving outcome in colorectal cancer-the manual. 1997. www. dh.gov.uk/en/Publicationsandstatistics/Publications/ PublicationsPolicyAndGuidance/DH_4006658.

22 Devbhandari M, Yang S, Quennell P, Krysiak P, Shah R, Jones M. Lung cancer resection rate in south Manchester: is it comparable to international standards? Results of a prospective tracking study. Interact Cardiovasc Thorac Surg 2007;6:712-4

23 Hospital Episode Statistics (HES) Online. About HES. 2009. www. hesonline.nhs.uk/Ease/servlet/ContentServer? sitelD=1937\& categorylD=87.

24 Hospital Episode Statistics (HES) Online. HES user guide. 2009 www. hesonline.nhs.uk/Ease/servlet/ContentServer? sitelD $=1937$ \& categorylD $=403$

25 Office of Population Censuses and Surveys. Tabular list of classification of surgical operations and procedures. HMSO, 1990

26 Tilney H, Heriot A, Purkayastha S, Antoniou A, Aylin P, Darzi, A, et al. A national perspective on the decline of abdominoperineal resection for rectal cancer. Ann Surg 2008;247:77-84.

27 Noble M, Wright G, Dibben C, Smith GAN, McLennan D, Anttila C, et al. The English indices of deprivation 2004 (revised): report to the office of the deputy prime minister. 2009. www.communities.gov. uk/documents/communities/pdf/131206.pdf

28 Snijders T, Bosker R. Multilevel analysis. Sage, 1999.

29 Dixon J, Sanderson C, Elliott P, Walls P, Jones J, Petticrew M. Assessment of the reproducibility of clinical coding in routinely collected hospital activity data: a study in two hospitals. J Public Health Med 1998;20:63-9.

30 Garout M, Tilney H, Tekkis P, Aylin P. Comparison of administrative data with the Association of Coloproctology of Great Britain and Ireland (ACPGBI) colorectal cancer database. Int J Colorectal Dis 2008;23:155-63.

31 Schrijvers C, Mackenbach J, Lutz JM, Quinn M, Coleman M. Deprivation, stage at diagnosis and cancer survival. Int J Cancer 1995;63:324-9.

32 Hole D, McArdle C. Impact of socioeconomic deprivation on outcome after surgery for colorectal cancer. Br J Surgery 2002;89:586-90.

33 Harris A, Bowley D, Stannard A, Kurrimboccus S, Geh J, Karandikar S. Socioeconomic deprivation adversely affects survival of patients with rectal cancer. Br J Surg 2009;96:763-8.

34 Downing A, Prakash K, Gilthorpe M, Mikeljevic J, Forman D. Socioeconomic background in relation to stage at diagnosis, treatment and survival in women with breast cancer. Br J Cancer 2007;96:836-40. 
35 Fisher B, Anderson S, Bryant J, Margolese R, Deutsch M, Fisher E, et al. Twenty-year follow-up of a randomised trial comparing total mastectomy, lumpectomy, and lumpectomy plus irradiation for the treatment of invasive breast cancer. $N$ Engl J Med 2002;347:1233-41.

36 Royal College of Surgeons of England. First annual report of the national mastectomy and breast reconstruction audit 2008. 2008. www.rcseng.ac.uk/news/first-annual-report-of-the-nationalmastectomy-and-breast-reconstruction-audit-2008.

37 Collins ED, Moore C, Clay K, Kearing S, O'Connor A, Llewellyn-Thomas $\mathrm{H}$, et al. Can women with early-stage breast cancer make an informed decision for mastectomy? J Clin Oncol 2009;27:519-25.

38 Katz J. Patient preferences and health disparities. JAMA 2001;286:1506-9.

39 Cancer Research UK. UK lung cancer incidence statistics. 2009. http://info.cancerresearchuk.org/cancerstats/types/lung/ incidence/.

40 Brown S, Hole D, Cooke T. Breast cancer incidence trends in deprived and affluent Scottish women. Breast Cancer Res Treat 2007;103:233-8.

41 NHS Information Centre for Health and Social Care. National lung cancer audit. 2009. www.ic.nhs.uk/webfiles/Services/NCASP/ audits\%20and\%20reports/ IC23090809_NHS_IC_Lung_Cancer_AUDIT_2009_Interactive_for_ web.pdf

42 Morris M, Quirke P, Thomas JD, Fairley L, Cottier B, Forman D. Unacceptable variation in abdominoperineal excision rates for rectal cancer: time to intervene? Gut 2008;57:1690-7.

43 Taylor A, Cheng K. Social deprivation and breast cancer. J Public Health Med 2003;25:228-33.

44 Henley N, Hole D, Kesson E, Burns H, George W, Cooke T. Does deprivation affect breast cancer management? Br J Cancer 2005;92:631-3.

45 Wyld L, Reed M. The role of surgery in the management of older women with breast cancer. Eur J Cancer 2007;43:2253-63.

46 Wyld L, Garg D, Kumar I, Brown H, Reed M. Stage and treatment variation with age in postmenopausal women with breast cancer: compliance with guidelines. Br J Cancer 2004;90:1486-91.

47 Imperatori A, Harrison R, Leitch D, Rovera F, Lepore G, Dionigi G, et al. Lung cancer in Teeside (UK) and Varese (Italy): a comparison of management and survival. Thorax 2006;61:232-9.
48 Damhuis R, Schutte P. Resection rates and postoperative mortality in 7899 patients with lung cancer. Eur Respir J 1996;9:7-10.

49 Myrda G, Lamberg K, Lambe M, Ståhle E, Wagenius G, Holmberg L. Regional differences in treatment and outcome in non-small cell lung cancer: a population-based study (Sweden). Lung Cancer 2009;63:16-22.

50 Martin-Ucar A, Waller D, Atkins J, Swinson D, O’Byrne K, Peake M. The beneficial effects of specialist thoracic surgery on the resection rate of non-small-cell lung cancer. Lung Cancer 2004;46:227-32.

51 Laroche C, Wells F, Coulden R, Stewart S, Goddard M, Lowry E, et al. Improving surgical resection rate in lung cancer. Thorax 1998;53:445-9.

52 Jack R, Guildford M, Ferguson J, Møller H. Explaining inequalities in access to treatment in lung cancer. J Eval Clin Pract 2006;12:573-82.

53 Peake M, Thompson S, Lowe D, Pearson M. Ageism in the management of lung cancer. Age Ageing 2003;32:171-7.

54 McCarthy M, Datta P, Khacharyan A, Coleman M, Rachet B. Would compliance with cancer care standards improve survival for breast, colorectal and lung cancers? J Epidemiol Community Health 2008;62:650-4.

55 Coleman M, Rachet B, Woods L, Mitry E, Riga M, Cooper N, et al. Trends and socioeconomic inequalities in cancer survival in England and Wales up to 2001. Br J Cancer 2004;90:1367-73.

56 Nur U, Racheta B, Westlake S, Cooper N, Alexe D, Khachatryan A, et al. Cancer survival, England, patients diagnosed 2000-2004 and followed up to 2005: one-year and five-year survival for 21 common cancers, by sex and age. 2008. www.statistics.gov.uk/downloads/ theme_health/cancer-survival-Eng-2000-2004.pdf.

57 Graham H. Tackling inequalities in health in England: remedying health disadvantages, narrowing health gaps or reducing health gradients? J Soc Policy 2004;33:115-31.

58 Verdecchia A, Francisci S, Brenner H, Gatta G, Micheli A, Mangone L, et al. Recent cancer survival in Europe: a 2000-02 period analysis of EUROCARE-4 data. Lancet Oncol 2007;8:784-96.

59 Neal R, Allgar V. Sociodemographic factors and delays in the diagnosis of six cancers: analysis of data from the National Survey of NHS Patients: Cancer. Br J Cancer 2005;92:1971-5.

60 Cooper Z, McGuire A, Jones S, Le Grand J. Equity, waiting times, and NHS reforms: retrospective study. BMJ 2009;339:b3264.

Accepted: 19 October 2009 